\title{
Outward FDI and Local Employment Growth in Italy*
}

\author{
Stefano Federico ${ }^{\dagger}$ and Gaetano Alfredo Minerva ${ }^{\ddagger}$
}

June 30, 2006

\begin{abstract}
Using several data sources, we assess the impact of Italy's outward foreign direct investment (FDI) on local employment growth between 1996 and 2001 for 12 manufacturing industries and 103 administrative provinces. Our main result is that, controlling for the local industrial structure and area fixed effects, FDI is associated with faster local employment growth, relatively to the national industry average. We also find that employment in small plants is not negatively influenced by higher levels of FDI. Our findings do not support therefore the idea that FDI is detrimental to local employment growth in the home country.
\end{abstract}

Keywords: Foreign direct investment; agglomeration; employment growth. JEL Classification: C21; F21; F23.

\footnotetext{
${ }^{*}$ A previous version of this paper circulated under the title "Fear of Relocation? Assessing the Impact of Italy's FDI on Local Employment" as Quaderno n. 102/2005 of the Department of Economics and Quantitative Methods of the University of Piemonte Orientale "A. Avogadro". We would like to thank for valuable suggestions Eliana Baici, Giorgio Barba Navaretti, Piero Cipollone, Aldo Goia, Peter Nunnenkamp, Gianmarco Ottaviano, participants to the 1st Italian Congress of Econometrics and Empirical Economics at the University Ca' Foscari in Venice, the CNR Meeting on International Economics and Development at the University of Urbino, the 2nd Euroframe Conference in Vienna, the ECB/CEPR Labour Market Workshop at the European Central Bank in Frankfurt-am-Main, and seminars in Novara and Castelló de la Plana. Minerva gratefully acknowledges financial support from the Italian Ministry for University and Research (FIRB project $n$. RBNE03YT7Z). The data on FDI are used under confidentiality arrangements. The views expressed here are our own and do not necessarily reflect those of the Bank of Italy.

${ }^{\dagger}$ Banca d'Italia, Sede di Genova. Via Dante 3, 16121 Genova, Italy. E-mail: stefano.federico@bancaditalia.it

${ }^{\ddagger}$ Dipartimento di Scienze Economiche, Università di Bologna. Strada Maggiore 45, 40125 Bologna, Italy. E-mail: minerva@spbo.unibo.it
} 


\section{Introduction}

As an increasing number of firms choose to move production abroad, the debate on the impact of such strategies on domestic employment has greatly intensified. Relocation, especially in low-wage countries, is often evoked in the public opinion as a major determinant of job losses, at the expenses of unskilled labor. This idea has received support among many politicians in various countries, leading to the draft or the approval of measures aimed at imposing penalties to firms investing or relocating abroad. Given its high policy relevance, the topic has been investigated in several studies, whose focus is generally limited to multinational firms.

However, the effects of foreign direct investment (FDI) may well extend to other, nonmultinational, companies. For instance, local suppliers of the investing firm could suffer as they are replaced by foreign suppliers, closer to the new plant built abroad. On the other hand, the setting up of a foreign affiliate may create new demand for intermediate inputs from the home-country producers. Policy makers are clearly more interested in the net effect of FDI on the whole local area, rather than only on the multinational firms. The lack of evidence on this topic is even more surprising as spillovers and externalities from FDI in the host economy have instead been the subject of a vast literature. Similar mechanisms are plausibly at work in the home economy too: market and non-market interactions following outward FDI may indeed have an influence on home suppliers and, more generally, home labour markets.

This paper addresses therefore the issue of the home-country effects of FDI, focusing on the employment performance of the local area from which the investments originate. Drawing from the literature on agglomeration economies, we estimate an employment growth regression (Glaeser, Kallal, Scheinkman, and Shleifer, 1992, Henderson, Kuncoro, and Turner, 1995 and Combes, 2000), which relates changes in employment levels, by local area and industry, to the local industrial structure (specialization, variety, average plants' size, etc.). We modify the standard regression adding, together with other controls, a measure related to FDI, so that we explain employment dynamics also as the outcome of the intensity of investment abroad. The analysis is carried out for the period 1996-2001 at a very fine level of disaggregation (103 Italian administrative provinces, corresponding to NUTS3 partitioning, and 12 manufacturing industries), which is an ideal viewpoint for an investigation of the effects of FDI on the local employment performance. We choose to 
concentrate on manufacturing because concerns about job losses in that sector have been widespread.

Several data sources are used. First, an innovative database coming from Ufficio Italiano dei Cambi (UIC) provides information on Italy's FDI outflows not only by industry and destination country but also by local area of origin. Another advantage of the data is that they cover a wide range of equity-type internationalization of production, including greenfield investments and foreign takeovers. This database is then matched with two waves of the Censimento dell'Industria e dei Servizi by Istituto Nazionale di Statistica (Istat), from which we derive local employment growth as well as the set of variables describing local industrial structure. Finally, we use several waves of Centrale dei Bilanci, a firm-level database collecting information for some 40,000 firms in Italy, from which we derive further control variables, aggregated at the local level.

Our results are the following. Controlling for the local industrial structure and area fixed effects, local employment growth is positively associated with higher levels of FDI, especially toward advanced countries. This finding should not reflect unobserved variables that simultaneously influence employment and FDI, biasing the estimates, as it is robust to the inclusion of other performance indicators (exports, TFP growth, TFP level, domestic capital growth). The positive impact of FDI is concentrated in some capital-intensive industries; no evidence of a negative relation is found for any other industry, including traditional sectors such as textile, clothing and leather. Our data allow us also to provide a first estimate, much needed in the literature, of the effect of FDI on non-multinational companies: small plants, which are presumably not involved in foreign investments, do not seem to be negatively affected by FDI generated from their local area and industry.

The rest of the paper is structured as follows. The next section briefly reviews the related empirical literature. Section 3 builds the theoretical underpinnings to our analysis, while section 4 presents the data. The econometric specification is described in section 5 , and the results are illustrated in section 6 . Section 7 concludes.

\section{Related literature}

Before briefly reviewing the literature, we stress that the perspective we take is broader than that usually taken in the studies on multinationals, since we are able to measure 
with our FDI variable all types of foreign investments, including those that deal with non-control participation shares (below $30 \%$ of equities of foreign companies), and with mergers and acquisitions. So far, the literature has focused mainly on employment effects on multinational companies, looking at how parent employment responds to changes in foreign affiliate's wages (Brainard and Riker, 1997, Braconier and Ekholm, 2000, Konings and Murphy, 2001).

One of the first empirical assessments of the effect of FDI on employment was made by Brainard and Riker (1997), who estimate an equation of U.S. multinationals labor demand across different plant locations. The coefficients on cross-elasticity of substitution provide then information on whether foreign affiliate labor is complement or substitute to parent labor. They find that the cross-elasticity between the parents and the affiliates is less than one, implying only partial substitution. Substitution between affiliates in different countries is instead markedly higher, especially for low value-added industries and for affiliates located in countries with similar levels of development. They conclude that labor in the U.S. does compete only at the margin with labor abroad, and that employment shifting takes place predominantly between foreign affiliates in less developed countries. Other studies based on the same methodology find similar results: contrary to conventional wisdom, employment in foreign affiliates located in low-wage countries appears to be complementary to home employment, while there is substitution between the latter and employment in advanced countries. ${ }^{1}$

However, as convincingly argued in Barba Navaretti, Venables et al. (2004, p. 222), the results of these studies are conditional on the multinational having already invested abroad. In other words, this approach is not able to deal with the potential substitution effect which takes place when a company moves production activities away from home for the first time. Another important limitation of this approach is that it ignores the external effects of FDI on home non-multinational companies, such as local suppliers. As regards the first point, Barba Navaretti and Castellani (2004) suggest that using appropriate matching techniques allows to identify the effect of the first investment abroad; applying this method to a sample of Italian companies they find no evidence in favour of the

\footnotetext{
${ }^{1}$ See Braconier and Ekholm (2000) on Swedish multinationals, and Konings and Murphy (2001) on European multinationals and their affiliates located in former EU-15 countries and in Eastern Europe. In another work, Bruno and Falzoni (2003) employ U.S. industry-level data.
} 
hypothesis of a negative effect of FDI on firms' performance, including employment. The second limitation, concerning the impact of FDI on non-multinational companies, still needs to be explored, and our work is a first step in this direction.

This study is also related to another strand of the literature, looking at the effects of FDI on the labor intensity of home-country production. Labour intensity is shown to depend not only on the location of the affiliates, but also on certain structural features of the home country. As evidenced by Blomstrom, Fors and Lipsey (1997), larger affiliate production implies a lower labor intensity in the U.S., while the opposite is observed for Sweden. This difference presumably reflects different investment strategies, with US firms allocating production activities across countries in order to exploit factor price differences, and Swedish affiliates more engaged in selling to local customers. Lipsey, Ramstetter and Blomstrom (2000) extend the analysis to Japan, finding a higher labor intensity in parent companies doing more FDI. Looking at Italian regions, with an approach related to ours because the unit of analysis is a combination of geographical areas and manufacturing industries, Mariotti, Mutinelli and Piscitello (2003) show that larger employment in affiliates located in developing countries is associated with lower labor intensity at home, consistently with the allocation of labor-intensive activities to low-wage countries; the opposite effect is observed for affiliates located in advanced economies.

\section{Theoretical underpinnings}

This section presents a simple theoretical model which clarifies how FDI can have an impact on local employment. Suppose that each combination of province, $p \in P$, and industry, $i \in I$, is a separate competitive entity producing a single good, $Y$, traded in national and international markets, according to the following production function:

$$
Y_{p, i}=A_{p, i}\left[f\left(L_{p, i}, K_{p, i}^{h}, K_{p, i}^{f}\right)\right]
$$

where $A_{p, i}$ is a measure of productivity in the province-industry (P-I hereafter), $L_{p, i}$ is labour, $K_{p, i}^{h}$ is domestic capital, and $K_{p, i}^{f}$ is capital employed abroad. The profit function of the representative firm is:

$$
\pi_{p, i}=s_{p, i} A_{p, i} f\left(L_{p, i}, K_{p, i}^{h}, K_{p, i}^{f}\right)-w_{p} L_{p, i}-r_{p}\left(K_{p, i}^{h}+K_{p, i}^{f}\right)
$$


where $s_{p, i}$ is the price of the good, taken as given due to perfect competition among producers, $w_{p}$ and $r_{p}$ are the wage rate and the rental rate of capital respectively in province $p$ (assumed to be constant across sectors in each province). Given $s_{p, i}, w_{p}$, and $r_{p}$, the representative firm belonging to a specific P-I maximizes profits with respect to labour $L_{p, i}$. We assume that the acquisition of foreign capital, $K_{p, i}^{f}$, is financed entirely in local credit markets, and that it is exogenously determined.

Assumption. Foreign capital holdings $K_{p, i}^{f}$ are an exogenous variable, determined outside our model.

The first order condition with respect to labour $L_{p, i}$ entails:

$$
\frac{\partial \pi_{p, i}}{\partial L_{p, i}}=0 \Rightarrow s_{p, i} A_{p, i} \frac{\partial f\left(L_{p, i}, K_{p, i}^{h}, K_{p, i}^{f}\right)}{\partial L_{p, i}}=w_{p}
$$

At this point we assume a specific functional form for $f\left(L_{p, i}, K_{p, i}^{h}, K_{p, i}^{f}\right)$. Let us assume it is:

$$
f\left(L_{p, i}, K_{p, i}^{h}, K_{p, i}^{f}\right)=\left(L_{p, i}\right)^{\alpha}\left(K_{p, i}^{h}\right)^{\beta}\left(K_{p, i}^{f}\right)^{\delta_{i}}
$$

where $\alpha$ and $\beta$ are strictly greater than zero and less than one, while we allow the parameter $\delta_{i}$ to be greater or lower than zero. In this manner we do not make a specific hypothesis about whether domestic production is negatively or positively affected by foreign capital. Being an exogenous variable, determined outside our model, $K_{p, i}^{f}$ is not a control variable but instead can be classified as a state variable. Since $\delta_{i}$ is indexed with respect to the industrial sector $i$, we allow in principle for different effects of foreign capital on home production across different industrial sectors. In other terms, we are not imposing neither a given sign of $\delta_{i}$ nor a uniform effect across industries. The partial derivative of $f(\cdot)$ with respect to $L_{p, i}$ is:

$$
\frac{\partial f(\cdot)}{\partial L_{p, i}}=\alpha\left(L_{p, i}\right)^{\alpha-1}\left(K_{p, i}^{h}\right)^{\beta}\left(K_{p, i}^{f}\right)^{\delta_{i}}
$$

and substituting in (1) we get

$$
L_{p, i}=\left(\frac{\alpha s_{p, i} A_{p, i}}{w_{p}}\right)^{1 /(1-\alpha)}\left(K_{p, i}^{h}\right)^{\beta /(1-\alpha)}\left(K_{p, i}^{f}\right)^{\delta_{i} /(1-\alpha)}
$$

This expression gives equilibrium labour demand $L_{p, i}$ as a function of variables and parameters of the model. A few more assumptions lead us to the final equation that will 
be at the basis of our empirical work. We assume that local prices $s_{p, i}$ are the product of a national, industry-specific, component $\lambda_{i}$, and an idiosyncratic province-wide component $\phi_{p}, s_{p, i}=\lambda_{i} \phi_{p}$. Even though goods are traded on the same national and international markets, there exists a residual component $\phi_{p}$ that makes the price prevailing in a local area higher or lower than the national average price $\lambda_{i}$ in industry $i$. As the Italian labor market is heavily regulated, wages are assumed to be given in each local area $p$, irrespectively of the sector $i$, and we assume that firms can hire as much labor they want at the prevailing rate $w_{p}$. Equation (3) represents then equilibrium employment. ${ }^{2}$

Taking the logarithm of (3) and differentiating with respect to time, the growth rate of employment at the local level is:

$$
\frac{\mathrm{d} L_{p, i}}{L_{p, i}}=\frac{1}{1-\alpha} \frac{\mathrm{d} s_{p, i}}{s_{p, i}}+\frac{1}{1-\alpha} \frac{\mathrm{d} A_{p, i}}{A_{p, i}}+\frac{\beta}{1-\alpha} \frac{\mathrm{d} K_{p, i}^{h}}{K_{p, i}^{h}}+\frac{\delta_{i}}{1-\alpha} \frac{\mathrm{d} K_{p, i}^{f}}{K_{p, i}^{f}}-\frac{1}{1-\alpha} \frac{\mathrm{d}\left(w_{p}\right)}{w_{p}}
$$

that can be written also as

$$
\frac{\mathrm{d} L_{p, i}}{L_{p, i}}=\frac{1}{1-\alpha} \frac{\mathrm{d}\left(A_{p, i}\right)}{A_{p, i}}+\frac{\beta}{1-\alpha} \frac{\mathrm{d} K_{p, i}^{h}}{K_{p, i}^{h}}+\frac{\delta_{i}}{1-\alpha} \frac{\mathrm{d} K_{p, i}^{f}}{K_{p, i}^{f}}+\frac{1}{1-\alpha} \frac{\mathrm{d}\left(\phi_{p} / w_{p}\right)}{\phi_{p} / w_{p}}+\frac{1}{1-\alpha} \frac{\mathrm{d} \lambda_{i}}{\lambda_{i}}
$$

where the growth rate of employment in each P-I is a function of the growth rates of productivity, domestic capital, foreign capital, relative price $\phi_{p} / w_{p}$ defined in each province, and the industry-wide component of the price of the final good, $\lambda_{i}$. It is then possible to perform estimation of (5). As long as $\alpha<1$, the sign of the coefficient on the growth rate of $K_{p, i}^{f}$ is the same of $\delta_{i}$. The model highlights that, when empirically assessing the impact of FDI on local employment, it is important to control for the growth rates of aggregate productivity and home capital, in addition to local area and industry dummies, especially if they turn to be correlated with foreign capital holdings. Otherwise we would face the well-known omitted variables bias. The Appendix 8.1 provides an extension of the model to the case where labour enters the production function of the multinational firm both

\footnotetext{
${ }^{2}$ Assuming a perfectly elastic labor supply, the model implies a monotone relation between changes in productivity and changes in employment. Recent studies have suggested that this relation breaks down when firms face a downward-sloping demand curve and the elasticity of the demand of the good is low (Combes, Magnac and Robin, 2004) or when labor supply is not independent from local conditions (see the discussion in Cingano and Schivardi, 2004). It should be remarked however that the focus of our study is not the relation between productivity and employment but the effect of FDI on the latter. The model should then be considered just as a framework for the empirical analysis, showing the conditions under which we get an unbiased estimate of the impact of FDI.
} 
directly and indirectly, through the supply of an intermediate good which uses only labour as input.

\section{Description of the data}

Our data come from several sources. The first is the Italian Census of Industrial and Services Sectors, Censimento dell'Industria e dei Servizi, carried out by Istat (Italian Statistical Institute). We use the two most recent waves, relative to 1996 (intermediate Census) and 2001. Data on employment and on the number of plants and firms are provided at a very fine level of disaggregation (in terms of location as well as industry classification). To match our data on FDI, which are only available on a less detailed basis, we employ Istat data aggregated up to 103 spatial units (administrative provinces) and 12 manufacturing industries. ${ }^{3}$ It is important to remind that census data cover the universe of Italian plants, including smaller units, which were instead often unavailable in many previous studies. From Istat we also get data on exports by industry, local area of origin, and destination country; these data refer again to the universe of Italy's firms and are used to build a control variable.

Census data do not provide information on capital stock, value added, intermediates' consumption. We therefore use Centrale dei Bilanci, CeBil hereafter, a large dataset which annually reports balance-sheet information for between 30,000 and 40,000 firms. This allows us to aggregate data from the firm level to the P-I level and build measures of domestic capital stock and total factor productivity changes. As they are used by banks in granting loans, data are carefully controlled and very reliable. They have already been used in several studies, also in the context of the agglomeration literature as in Cingano and Schivardi (2004), where a detailed comparison between CeBil and the universe of Italian firms can be found. The key points to stress are that firms in CeBil tend to be higher-quality borrowers, therefore they are on average larger and better performing than the universe of Italian firms. The sample selection should not be a concern for our work, because the dataset represents about half of total manufacturing employment and a larger share of sales. Furthemore, it includes a very large share of Italian multinational companies, so that the control variables for the growth rates of productivity and home

\footnotetext{
${ }^{3}$ See Appendix 8.2 for the list of manufacturing industries.
} 
capital derived from CeBil are in principle capable of eliminating any spurious correlation between FDI and local employment growth.

The last source is a database provided by UIC, which collects FDI data in order to produce Italy's balance of payments statistics. It includes the outward FDI flows by industry, source province and destination country, for the period 1997-2001.4 The distinction between investments (acquisition of foreign activities by Italian residents) and divestments (selling of foreign activities by Italian residents) is also available. Thanks to the information on the source province and industry, we are able to estimate whether and in which direction higher levels of FDI do influence local employment. The detail on the destination countries is particularly useful since it allows us to distinguish between FDI towards advanced and developing economies, where the motivation behind the investment, and consequently its effects on home employment, can differ in many respects.

Although quite common in the empirical literature on FDI, the use of balance of payments data faces a number of problems (Lipsey, 2001). First, they do not include FDI that are financed on foreign capital markets (if, for instance, the foreign affiliate raises money on the local market by issuing a bond or through an IPO). Second, the balance of payments statistics tend to systematically underestimate the value of the assets held abroad, presumably as a consequence of tax-avoiding behaviors. Looking at the case of Italy, Committeri (1999) finds indeed that actual foreign assets are larger than those appearing in the official data, although the discrepancy is moderate. Third, for each transaction, FDI data generally report only the immediate recipient, which however may not coincide with the ultimate recipient: for instance, if an Italian company wants to build a plant in Brazil, but the money is first sent to a holding located in Luxembourg and only afterwards goes to Brazil, FDI data will report only the first step of this chain of transactions (from Italy to Luxembourg).

While these problems may be very important in theory, in practice they have a minor relevance. FDI flows to those countries where production should not be the main reason for the investments are less than 10 per cent of total flows (typically very small-sized countries with a favorable tax legislation; the list is provided in Appendix 8.3). In line with evidence on world FDI, the large majority of Italian investments goes towards advanced (Oecd)

\footnotetext{
${ }^{4}$ For more details on the FDI balance of payments statistics see IMF (1993), Banca d'Italia and Ufficio Italiano dei Cambi (2004).
} 
economies, while the share of developing (non-Oecd) countries is much smaller (77 and 14 per cent respectively). More generally, the distribution of FDI data is remarkably similar to that of foreign affiliates of Italian companies. Federico (2006) compares UIC data with the Reprint database (Cominotti, Mariotti, Mutinelli, and Piscitello, 2002), which provides information on the foreign affiliates of many Italian companies and is the most complete alternative source on the subject. Overall, the correlation between the sum of flows of FDI from 1997 to 2001 and the stock of foreign affiliates' employment in 2000, across nine industries and six destination areas, is quite high (0.70); similar results are obtained when one industry is dropped at a time, meaning that the correlation is not driven by a single industry. Furthermore, when looking at the provenance of foreign activities, both sources point to the same picture: around three-quarters of FDI come from the North-West of Italy, whose share in terms of foreign employment, according to Reprint, is only slightly smaller. ${ }^{5}$

A brief look at some raw data concludes this section. Between 1996 and 2001 manufacturing employment in Italy increased by 0.9 per cent (about 43,000 people). This small increase masks however considerable dispersion among regions as well as industries. Table 1 reports the three regions with the best or the worst (absolute) employment performance, showing that regions at similar levels of development (Emilia-Romagna and Veneto on one hand, Lazio, Piemonte and Lombardia on the other) had opposite performances. Notice also that the two latter regions are also those with the largest shares on total FDI flows. While this evidence seems to point to a negative relation between FDI and employment, the picture becomes more blurred once we look at data by industry of Table 2 . In the Textiles, apparel and leather industry, where job losses were above 100,000 persons, FDI flows represent only a tiny share of total flows. Among the three industries with high levels of FDI (Office equipment and computers; Industrial machinery; Transport vehicles), only in the latter employment actually fell, while the first recorded a marked growth. To clarify the issue, we need to carry a more sophisticated analysis, whose methodology is presented in the next section.

\footnotetext{
${ }^{5}$ Analogous evidence holds for another country, Japan. Looking at cumulative sums of FDI flows and overseas employment for Japanese manufacturing firms over the period 1976-1989, Head and Ries (2002, p. 88, footnote 4) find a correlation of 0.92 . This result confirms that there is a strong relation between the sum of FDI flows and stock data regarding internationalization of production activities.
} 
[Insert Table 1 about here]

[Insert Table 2 about here]

\section{$5 \quad$ Methodology and econometric specification}

Our econometric analysis is based on a regression whose dependent variable is employment growth at the local level, according to the theoretical underpinnings described in section 3. The choice of the unit of analysis, the province-industry P-I, is dictated by the unavailability of FDI data with a deeper detail. With respect to a finer level of spatial aggregation such as local labor systems ${ }^{6}$ we may lose some precision in the estimation, because the change in employment as well as the other variables are averaged over a greater and less homogeneous area. However, we are confident that our choice of P-I should not have a major impact on our results: several studies have considered Metropolitan Statistical Areas, a spatial unit that can be thought to match more closely Italy's administrative provinces (Glaeser et al. 1992, Henderson et al. 1995).

The dependent variable is the employment growth rate of industry $i$ in province $p$ between 1996 and 2001. It is useful to stress that this is total employment in the P-I, as we are not able to distinguish between multinational companies and the rest of firms. Approximating growth rates with logarithms, we have:

$$
l_{p, i}=\log \left(\frac{L_{p, i, 2001}}{L_{p, i, 1996}}\right)
$$

where $L_{p, i, t}$ is employment in province $p$ and industry $i$ for a given year $t$.

Turning to the growth rate of foreign capital stock, it can be written as:

$$
\frac{\mathrm{d} K_{p, i}^{f}}{K_{p, i}^{f}}=\log \left(\frac{K_{p, i, 1997}^{f}+\sum_{t} \mathrm{FDI}_{p, i, t}}{K_{p, i, 1997}^{f}}\right)=\log \left(1+\frac{\mathrm{fdi}_{p, i}}{K_{p, i, 1997}^{f}}\right)
$$

with

$$
\operatorname{fdi}_{p, i} \equiv \sum_{t} \mathrm{FDI}_{p, i, t}
$$

\footnotetext{
${ }^{6}$ Local labor systems are the spatial unit generally used in the literature on agglomeration in Europe. The main advantages of working with local labor systems are twofold. First, their larger number yields more degrees of freedom: Italy is divided into 784 local labor systems, and 103 provinces. Second, being identified on the basis of workers' daily mobility, they are, by construction, more homogenous in terms of local industrial structure.
} 
where $\mathrm{FDI}_{p, i, t}$ are positive flows of outward FDI, deflated to 1995 euro, and $t$ are years 1997, 1998, 1999, and $2000 .{ }^{7}$ Here we face a severe limit due to the lack of data. Actually, we would need data on the stock of FDI at the beginning of 1997 for each P-I. Unfortunately, such data do not exist. The only way we can deal with this is simply not normalizing with respect to the initial foreign capital stock, and approximating $\mathrm{d} K_{p, i}^{f} / K_{p, i}^{f}$ with the logarithm of $\left(\mathrm{fdi}_{p, i}+1\right)$ only. ${ }^{8}$ However, measuring FDI flows in absolute terms, we carry the risk of underestimating the effect of FDI in small P-Is: potentially significant employment growth variations in small local areas would be then associated to small absolute flows, even though the growth rate of foreign capital stock had been significant. By the same line of reasoning, employment growth variations in those (large) P-Is responsible for the highest amount of FDI's absolute flows would be given more weight. ${ }^{9}$

Turning to the other variables, the regressors related to local industrial structure, taken at their 1996 values, are meant to capture (at least part of) the growth rate of real aggregate productivity $A_{p, i}$, in line with the literature on agglomeration economies. First, for each province-industry, we consider a measure of specialization of production in a given industry, computed as follows:

$$
\operatorname{spec}_{p, i}=\frac{L_{p, i}}{L_{p}}
$$

where $L_{p}$ is total manufacturing employment in province $p$.

Second, in order to capture the effect of local variety of production in the manufacturing industries other than the one $i$ under scrutiny, we introduce a Hirschman-Herfindahl type index, as in Henderson et al. (1995), measuring the degree of concentration of production in the $j \neq i$ industries in the local area. Actually we compute the inverse of such an index,

\footnotetext{
${ }^{7}$ We sum positive FDI flows over the years 1997-2000 on the basis of two different considerations. First, we do not have data for 1996, as the series only starts in 1997: this exclusion should have minor consequences, given that 1996 FDI flows represent only 12.2 per cent of 1996-2000 FDI flows (detailed aggregate statistics on the amount of FDI are available from the Relazione del Governatore annually published by the Bank of Italy). Second, we deliberately choose to exclude FDI flows relative to 2001, because the figures on employment for 2001, measured by Istat with reference to 22nd October of that year, were unlikely affected by FDI flows taking place in 2001 itself. In Appendix 8.4 we show how $\sum_{t} \mathrm{FDI}_{p, i, t}$ and $\mathrm{FDI}_{p, i, t}$ for each year are distributed.

${ }^{8}$ By adding one unit we avoid dismissing all the observations with zero FDI. A similar method has been employed for trade flows by Redding and Venables (2004).

${ }^{9}$ Notice however that in the simplified model we presented there is no depreciation of foreign capital. In a model with foreign capital depreciation, the initial capital stock would play a smaller role, thus limiting the bias mentioned in the text.
} 
so that, for each P-I, higher values indicate higher diversity (less concentration) of the surrounding industrial environment:

$$
\operatorname{div}_{p, i}=1 / \sum_{j \neq i}\left(\frac{L_{p, j}}{L_{p}-L_{p, i}}\right)^{2}
$$

We then consider a variable concerning the effect of the scale of production, measured by the average plant size:

$$
\operatorname{size}_{p, i}=\frac{L_{p, i}}{n_{p, i}}
$$

where $n_{p, i}$ is the number of plants in the P-I.

To sum up, a first approximation we use to model aggregate productivity dynamics at the local level is to assume that $\mathrm{d} A_{p, i} / A_{p, i}=h\left(\operatorname{spec}_{p, i}, \operatorname{div}_{p, i}, \operatorname{size}_{p, i}\right)$, with $h(\cdot)$ being a log-linear function of local variables.

We also add to the regression a set $\mathbf{X}_{\mathbf{p}}$ of spatial controls, i.e. dummy variables for the 103 provinces. The area fixed effects control for geographical position, local institutions, transport infrastructures, local wages, $w_{p}$, local rental rates, $r_{p}$ the idiosyncratic component of the final commodity's price, $\phi_{p}$, and all those province-specific factors affecting employment growth at the local level. Then we consider sectoral controls $\mathbf{S}_{\mathbf{i}}$, one for each industry, capturing specificities in employment growth variations that apply to Italian industries as a whole (for instance the industry-wide component of the final good's price, $\left.\lambda_{i}\right)$.

The baseline equation to be estimated through OLS is therefore the following, which corresponds to a standard employment growth regression, supplemented by the FDI term:

$$
\begin{aligned}
l_{p, i}=\alpha_{0}+\alpha_{1} \log \left(\operatorname{fdi}_{p, i}+1\right)+\alpha_{2} \log \left(\operatorname{div}_{p, i}\right)+\alpha_{3} \log \left(\operatorname{spec}_{p, i}\right) & +\alpha_{4} \log \left(\operatorname{size}_{p, i}\right) \\
& +\bar{\alpha}_{\mathbf{5}} \mathbf{X}_{\mathbf{p}}+\bar{\alpha}_{\mathbf{6}} \mathbf{S}_{\mathbf{i}}+u_{p, i}
\end{aligned}
$$

where $u_{p, i}$ is a random error, assumed to be normal and i.i.d., while $\bar{\alpha}_{\mathbf{5}}$ and $\bar{\alpha}_{\mathbf{6}}$ are vectors of coefficients on the dummy variables.

As we argued in section 3 , it is important to carefully control for the dynamics of the productivity term, $A_{p, i}$, and the dynamics of the stock of local capital, $K_{p, i}^{h}$. Equation (6) is a first step in this direction, since we control for local economic structure's variables and local-area fixed effects that affect $A_{p, i}$. This approach is still problematic for two reasons. First there is a chance that we are missing some relevant variables influencing the growth 
rate of $A_{p, i}$. Second, we do not control for the growth rate of domestic capital at all. We then supplement our data with variables retrieved from the firm-level database CeBil, computing the aggregate growth rates of nominal productivity and domestic capital stock in each P-I between 1996 and 2000. ${ }^{10}$ Both variables are the weighted averages of each individual firm's growth rate, using the firm's share in terms of value added and capital stock respectively. More formally, the aggregate total factor productivity growth is:

$$
\frac{\mathrm{d}\left(s_{p, i} A_{p, i}\right)}{s_{p, i} A_{p, i}}=\sum_{v \in\{p, i\}} \frac{h_{v, 1996}+h_{v, 2000}}{2} \log \left(\frac{\omega_{v, 2000}}{\omega_{v, 1996}}\right) \equiv \operatorname{gtfp}_{p, i}
$$

where $v$ is an individual firm located in a given P-I, $h_{v, t}$ is the share in terms of valueadded of that firm in its P-I in year $t$, and $\omega_{v, t}$ is the nominal productivity term (TFP) in year $t$. TFP is a residual term of a regression of deflated value added on employment and deflated capital, computed according to Levinsohn and Petrin (2003) estimator. ${ }^{11}$

With a similar reasoning the growth rate of local capital is approximated by:

$$
\frac{\mathrm{d} K_{p, i}^{h}}{K_{p, i}^{h}}=\sum_{v \in\{p, i\}} \frac{g_{v, 1996}+g_{v, 2000}}{2} \log \left(\frac{k_{v, 2000}^{h}}{k_{v, 1996}^{h}}\right) \equiv \operatorname{gcap}_{p, i}
$$

where $g_{v, t}$ is firm $v$ 's share of capital in year $t$ with respect to the total amount of capital hold by firms in the P-I. In the computation of both variables we only consider firms appearing in both 1996 and 2000 (13,371 firms). The firms were unequally spread among different P-Is, with some P-Is missing, so that capital and productivity growth data were aggregated up to $901 \mathrm{P}$-Is. Nonetheless, the spatial and sectoral distribution of firms in the balanced panel is highly representative of the actual distribution of employees. ${ }^{12}$

Finally, we consider two further variables in order to control for other factors which could simultaneously impact on employment and FDI biasing the link between labour

\footnotetext{
${ }^{10}$ The time span is the same used for FDI data, in order to control for any possible spurious correlation between employment growth and FDI via home capital and productivity. Using a 1996-2001 period does not affect our results.

${ }^{11}$ We tried also to construct our productivity measure as the growth rate of aggregate average productivity between 1996 and 2000, $\mathrm{d}\left(s_{p, i} A_{p, i}\right) /\left(s_{p, i} A_{p, i}\right)=\sum_{v \in\{p, i\}} h_{v, 2000} \omega_{v, 2000}-\sum_{v \in\{p, i\}} h_{v, 1996} \omega_{v, 1996}$, that allows us to include in the computation of the productivity index for each year also those firms that appear either in 1996 or in 2000. Employing this measure as a proxy of productivity growth our empirical estimates were not affected. For a discussion of different measures of aggregate productivity growth see Petrin and Levinsohn (2005).

${ }^{12}$ The correlation coefficient between the number of CeBil firms in each P-I and the employment level from Census data in 1996 is 0.90 . This means that the higher employment, the higher is the number of firms in CeBil.
} 
dynamics and FDI. We compute the initial $(t=1996)$ level of TFP in each P-I $\left(\operatorname{tfp}_{p, i}\right)$, supposing that more productive firms, and in aggregate more productive local areas, are more likely to invest abroad, following Helpman, Melitz and Yeaple (2004). The level is a weighted average of firm-level TFP (in logs), with weights being equal to each firm's share in terms of value added. Then, we look at exports, which are another form of internationalization that could foster employment growth and is correlated with FDI. To be sure that our results on FDI are not driven by exports we add to the regression the variable $\exp _{p, i}$, measuring the sum of flows of exports between 1997 and 2000, originated from a given P-I. Table 3 and Table 4 respectively show the descriptive statistics and the correlation matrix among the variables. Adding the other variables to the baseline equation, the final expression is:

$$
\begin{aligned}
l_{p, i}=\alpha_{0}+ & \alpha_{1} \log \left(\operatorname{fdi}_{p, i}+1\right)+\alpha_{2} \log \left(\operatorname{div}_{p, i}\right)+\alpha_{3} \log \left(\operatorname{spec}_{p, i}\right)+\alpha_{4} \log \left(\operatorname{size}_{p, i}\right) \\
& +\bar{\alpha}_{\mathbf{5}} \mathbf{X}_{\mathbf{p}}+\bar{\alpha}_{\mathbf{6}} \mathbf{S}_{\mathbf{i}}+\alpha_{7} \log \left(\exp _{p, i}\right)+\alpha_{8} \operatorname{gtfp}_{p, i}+\alpha_{9} \operatorname{gcap}_{p, i}+\alpha_{10} \operatorname{tfp}_{p, i}+u_{p, i}
\end{aligned}
$$

[Insert Table 3 about here]

[Insert Table 4 about here]

\section{Empirical results}

\subsection{Baseline estimation}

We estimate equation (6) on 1208 out of the 1236 observations that would result as a combination of 103 provinces and 12 industries; we are forced to drop 28 observations with zero employment in either 1996 or 2001. The results of the first set of estimates are presented in Table 5. Looking at the industrial structure variables in column [1], our results are generally in accordance with the previous literature. Local productive specialization has a negative impact on employment growth, as was found in Glaeser et al. (1992) and in a number of subsequent studies; on the contrary, diversity turns out to be positively related to labour dynamics. ${ }^{13}$ Our data support therefore the idea that sectors located in more diversified provinces had higher growth rates over the period 1996-2001, while

\footnotetext{
${ }^{13}$ Other studies suggest instead a negative effect of productive variety in industrial sectors (Combes 2000 and Cingano and Schivardi 2004 in their employment-based regressions); their results on specialization are on the contrary qualitatively similar to ours.
} 
more specialized provinces lagged behind, though the positive effect of diversity does not survive to the inclusion of the control for exports (column [3]). Furthermore, in line with many studies, a smaller average plant size benefits growth. As outlined in Combes (2000), this may simply reflect a life cycle story (newly-born firms are small and grow faster until they reach their optimal size).

[Insert Table 5 about here]

FDI appears to have a positive and statistically significant effect on local employment, suggesting that, relatively to the national industry average, local areas whose firms invest more abroad have a better employment performance. The magnitude of the coefficient can be be interpreted as follows: a $10 \%$ increase in FDI flows to advanced countries leads to roughly a $0.17 \%$ increase in employment growth. There are various reasons why FDI may not harm employment growth in the home country, while actually enhancing it. First of all, there is not necessarily a perfect investment-substitution between the home and the foreign country: firms may invest abroad in order to diversify or expand in foreign markets, without reducing at the same time the domestic capital stock. This is especially the case for cross-border mergers and acquisitions, which are included in our data. More generally, FDI may contribute to the growth of investing companies, as they gain improved access to distant markets or manage to reduce their operating costs; headquarters employment can rise as more labor is required in co-ordinating and supervising the activities of foreign affiliates. Finally, FDI may have a positive impact also on non-multinational companies, if the setting up of a foreign affiliate boosts demand for intermediate products from suppliers located in the home country. ${ }^{14}$

The empirical literature suggests that the degree of labor substitution induced by FDI may differ even widely between advanced and developing countries. It is therefore important to take into account the exact destination of Italy's FDI. Using UIC data, which include information about the destination countries, we break up total FDI in two variables: FDI to advanced countries and FDI to developing countries; we exclude FDI towards small countries because they are often not intended for production. The results,

\footnotetext{
${ }^{14}$ In unreported estimates, drawing on Combes et al. (2004) we decompose the dependent variable in two terms, the growth of the average plant size and the growth of the number of plants: FDI has a positive impact in both cases, suggesting that it simultaneously reinforces the competitiveness of investing firms and fosters plant creation.
} 
reported in column [2] of Table 5, show that the positive impact of FDI is concentrated in advanced countries, while in the case of FDI towards developing countries the coefficient is not significantly greater than zero. However the two variables are highly correlated at the P-I level (the correlation between $\mathrm{fdi}^{\mathrm{A}}$ and $\mathrm{fdi}^{\mathrm{D}}$ is 0.62 , from Table 4). This means that if a province-industry invests a lot abroad in advanced countries, it is likely that it will also invest in developing countries. While this is an interesting feature per se of our data, it introduces a multicollinearity problem in the econometric estimation. If FDI to advanced countries is omitted from the regression, the coefficient on FDI towards developing countries becomes significant, but remains smaller, around 0.009.

\subsection{Robustness}

In the next two columns of Table 5 we assess the robustness of our results to the inclusion of another form of internationalization which could boost employment while being correlated with FDI, i.e. exports. The introduction of the sum of export flows lowers the coefficient on $\operatorname{fdi}_{p, i}$ (from 0.017 to 0.012 ) but leaves it still significantly greater than zero (column [3]). Notice that, as expected, export flows on their own positively impacts on the performance of local areas' employment. Similar results are obtained in column [4], where the FDI variable is again divided in FDI to advanced and to developing countries. ${ }^{15}$

As a second robustness exercise, we add the productivity and home capital growth controls elaborated from CeBil, as in equation (7). As said earlier, only for a subsample of P-Is are they available so that the estimate is based on 899 observations. The consequences of selection induced by the inclusion of firm-level controls should be carefully isolated. To do so, we first run a preliminary regression (column [1]) where we focus on this subset of P-Is, without including the two CeBil variables, and then we replicate the estimate with their inclusion. The results are shown in Table 6. With respect to previous estimates, we notice a weaker effect of FDI, which is entirely induced by the mere selection of P-Is. In column [2], both TFP growth and capital growth are not significantly different from zero and their inclusion does not affect the coefficient on the FDI variable. The TFP level appears instead to have a positive impact on employment growth, consistently with the idea that employment performance is stronger in local areas where firms are initially more

\footnotetext{
${ }^{15}$ When controlling for exports according to the destination countries, advanced and developing, the results are unchanged.
} 
productive. In any case, these findings show that the positive and statistically significant effect of FDI does not reflect a spurious correlation with employment growth operating through the omission of productivity and home capital controls.

[Insert Table 6 about here]

\subsection{Industry specificities}

Sectoral specificities in the relation between FDI and employment could be hidden under the cross-industry regression of equation (6). To capture effects in single industries we build interaction variables between the FDI variable and industries' dummies. We run three separate regressions, one with FDI to the world, one including only advanced countries, and the other with FDI to developing countries. ${ }^{16}$ The model to be estimated is then modified in the following way:

$$
\begin{aligned}
l_{p, i}=\alpha_{0}+\alpha_{1} \log \left(\operatorname{fdi}_{p, i}+1\right)+\bar{\delta}_{\mathbf{1}} \mathbf{D}_{\mathbf{i}} \log \left(\operatorname{fdi}_{p, i}+1\right) & +\alpha_{2} \log \left(\operatorname{div}_{p, i}\right)+\alpha_{3} \log \left(\operatorname{spec}_{p, i}\right)+\alpha_{4} \log \left(\operatorname{size}_{p, i}\right) \\
& +\bar{\alpha}_{\mathbf{5}} \mathbf{X}_{\mathbf{p}}+\bar{\alpha}_{\mathbf{6}} \mathbf{S}_{\mathbf{i}}+\alpha_{7} \log \left(\exp _{p, i}\right)+u_{p, i}
\end{aligned}
$$

with $\bar{\delta}_{\mathbf{1}}$ the vector of coefficients on the interaction terms, and $\mathbf{D}_{\mathbf{i}}$ sectoral dummies. Nonmetallic mineral products is the reference sector, so that we dropped its dummy from the regression: its estimated coefficient, $\alpha_{1}$ in equation (8), turns to be conveniently close to zero. The other results are reported in Table 7, which shows, for each industry, the sum of $\alpha_{1}$ and the interaction term for the industry $i, \delta_{1, i}$, as well as the significance level of the $F$-test on the linear restriction $\alpha_{1}+\delta_{1, i}=0$; in this way, we are able to assess if the impact of FDI for a specific industry is significantly different from zero. FDI to advanced countries appears to significantly influence local employment in some capitalintensive industries (chemical products, industrial machinery, paper and printing, plastic and rubber products and, more weakly, food and beverage). No evidence of a negative and significant relation is found for any other industry, including traditional ones such as textile, clothing and leather. Coherently with our previous estimates, FDI to developing countries positively affect local employment growth, even though such a positive impact is statistically less clean.

[Insert Table 7 about here]

\footnotetext{
${ }^{16}$ The export control variable is built accordingly: in the first regression we consider export to the world, in the second and third export to advanced and developing countries respectively.
} 


\subsection{Extensions}

Italian census provides employment data disaggregated according to the dimension of the corresponding plant in terms of employees, so that we are able to regress separately employment growth in small plants (less than 50 employees) and employment growth in medium and large plants (50 and more). The rationale of this analysis is twofold. First, small plants are not likley to invest abroad; therefore, we can be fully confident that there is no spurious correlation between their employment growth and FDI, the latter being exogenous to small plants. Second, the analysis is interesting on its own, given the almost complete lack of evidence on the effects of FDI on non-multinational companies. The results are reported in the first two columns of Table 8 . We find that FDI has a positive and significant effect only on plants with at least 50 employees, while no significant effect is found for small plants. ${ }^{17}$ It is remarkable that there is no evidence of a negative effect of FDI on non-multinational companies located in the same P-I, such as those of small size.

So far we have made the implicit assumption that the effects of FDI on employment are restricted to the local area (and to the local firms) where multinational companies are headquartered. In this way we only measure the labor substitution effects in plants located in the same province of the headquarters. However, if multinational firms have establishments located in other provinces of Italy, one could expect that they also may be affected by FDI, in either directions: plants may be closed and production moved abroad, or they may benefit from the stronger competitiveness of the multinational firm. Fortunately, census data provide information not only on employment in local plants, but also on employment in all Italian plants belonging to firms headquartered in a given local area. We then replicate our estimates with a modified dependent variable, as we consider employment growth of local firms (i.e. headquartered in the province) relative to the Italian industry average. ${ }^{18}$ Analyzing the firms' employment growth regression

\footnotetext{
${ }^{17}$ When we look only at plants with 50 employees or more, the number of observation falls as the share of P-Is with zero employment in plants of such size rises. The results are unchanged if the threshold size is changed, either down to 20 employees or up to 100 employees.

${ }^{18}$ In this way we are still able to capture linkages between multinationals' headquarters and suppliers whose head offices are located in the same province of the multinationals' headquarter. We are not able instead to measure any more changes in the employment of local suppliers whose head office is in a different province. In both types of regression we cannot capture external effects on suppliers located in a different
} 
in the last column of Table 8, we still find a positive effect of FDI, although it is no longer significant (the coefficient is 0.008). Again there is no clean evidence about labor substitution, even though the point estimate of the FDI coefficient shrinks with respect to the plants' employment regression.

\section{Concluding remarks}

Public concerns about firms moving jobs abroad through FDI are increasingly loud. Only empirical analyses can shed light on this very important issue. Rather than focusing on multinational firms only, as in the previous literature, we tackled the problem from a different angle, comparing employment performance across local areas. Our measure of FDI encompasses the whole amount of investments abroad made by manufacturing multinational companies based in Italy between 1996 and 2000. Our findings should be viewed as complementary to the previous literature. Using a different methodology, which takes into account also non-multinational companies, and considering a broader range of FDI activities, there is no evidence suggesting a negative impact of FDI, including investments toward developing countries. Employment growth in local areas investing more abroad appears instead to be stronger than the industry average, especially in some capital-intensive sectors. Even when we look at small plants, which are presumably not directly involved in foreign activities, their employment does not seem to be negatively affected by FDI generated from their local area and industry. To the best of our knowledge, this is the first estimate in the literature of the effect of FDI on non-multinational companies.

It is useful to remind that our analysis has some limitations, due to data availability. First, we observe employment changes only on a five-year span, which is admittedly a relatively short time period. Therefore, we cannot completely exclude that our results may be driven by the business cycle or by sector-specific shocks. Furthermore, the observation period 1996-2001 is characterized by a positive business cycle: cost-cutting strategies, leading to restructuring and relocation, may be necessary in the adverse phases of the business cycle. Also, in the long run the negative effects of FDI may prevail, if there are externalities and the innovation rate in the home country's cluster falls (Basevi and Ottaviano, 2002). Second, production may be moved abroad not only through FDI, but province than the one of origin of the investment. 
also through non-equity agreements with foreign producers. For instance, using U.S. data, Antràs (2004) shows that non-equity agreements are more frequent in labor-intensive industries. In the present paper we are focusing on a specific part of the story concerning the link between international organization of production - only through FDI - and home performance. Third, a priori FDI may have different effects among low-skilled and highskilled workers, but unfortunately we have no data on the employment composition at the local level.

Although subject to these caveats, our findings appear to be supported by several pieces of evidence. The first comes from the geographical distribution of Italy's FDI: the majority of employees in foreign affiliates is still located in advanced countries and not in low-wage countries, where concerns about labor substitution are greater. Further evidence consistent with our results comes from a survey on a sample of Italian multinational firms, which were asked whether foreign activities had been beneficial or detrimental to their domestic employment. According to 63 per cent of firms, FDI had no significant effect on their labour force in Italy, and the impact was positive for 22 per cent of the companies; only for the remaining 15 per cent of firms - mainly in traditional industries - did foreign investments have a negative effect on home-country employment (Banca d'Italia, 2006). Using appropriate matching techniques, Barba Navaretti and Castellani (2004) compare performance among Italian firms and find that investing abroad improves both output and total factor productivity, while it has no significant effect on employment. All these findings seem to point to the same conclusion that the effect of FDI on home-country employment is generally not negative, and can even be positive in certain cases, at least as far as Italy is concerned. Extending the analysis to other countries is therefore an important task ahead for future research. 


\section{Appendix}

\subsection{A modified model}

The model described in Section 3 can be extended to the case in which two different goods are produced: an intermediate good, $X$, and a final good, $Y$. The intermediate good enters the production process to assemble the final good. The production function for the intermediate in each P-I is

$$
X_{p, i}=N_{p, i}
$$

where labour is normalized so that one worker produces exactly one unit of intermediates. Output $X_{p, i}$ enters the production function for the final good according to the expression

$$
Y_{p, i}=A_{p, i}\left[f\left(M_{p, i}, K_{p, i}^{h}, K_{p, i}^{f}\right)\right]^{\gamma} X_{p, i}^{1-\gamma}=A_{p, i}\left[f\left(M_{p, i}, K_{p, i}^{h}, K_{p, i}^{f}\right)\right]^{\gamma} N_{p, i}^{1-\gamma}
$$

where $A_{p, i}$ is a measure of productivity in the P-I, $M_{p, i}$ is labour employed in the production of final good, $K_{p, i}^{h}$ is capital employed at home, $K_{p, i}^{f}$ is capital employed abroad. So we assume that in the production process of the final good some foreign capital is needed in addition to home capital. We do not make any precise hypothesis about vertical integration or not of production of the intermediate good within the boundaries of the firm producing the final good. Let us consider the case under which the final good producer buys the intermediate good in the market (outside its boundaries), and let us assume that complete contracts are available. If we assume perfect competition in the intermediate sector, the wage rate going to workers producing the intermediate equals the price of the intermediate itself, so that the profit function of the final good producer is

$$
\pi_{p, i}=s_{p, i} A_{p, i}\left[f\left(M_{p, i}, K_{p, i}^{h}, K_{p, i}^{f}\right)\right]^{\gamma}\left[N_{p, i}\right]^{1-\gamma}-w_{p}\left(M_{p, i}+N_{p, i}\right)-r_{p}\left(K_{p, i}^{h}+K_{p, i}^{f}\right)
$$

where $s_{p, i}$ is the price of the final good, taken as given due to perfect competition among final good's producers, $w_{p}$ and $r_{p}$ are the wage rate and the rental rate of capital respectively, assumed to be given in each local area $p$, irrespectively of the sector $i$. At this point we stress that the profit function would remain the same under vertical integration. We are then allowed to say that profits' maximization with respect to $N_{p, i}$ in (9) is equivalent to maximization with respect to $X_{p, i}$. The representative multinational firm belonging to P-I maximizes profits, given $s_{p, i}, w_{p}$, and $r_{p}$, with respect to labour components $M_{p, i}$ and $N_{p, i}$, and home capital, $K_{p, i}^{h}$. As before, we treat foreign capital $K_{p, i}^{f}$ as exogenously 
determined. The first order conditions are:

$$
\begin{aligned}
& \frac{\partial \pi_{p, i}}{\partial M_{p, i}}=0 \Rightarrow s_{p, i} A_{p, i} \gamma\left(N_{p, i}\right)^{1-\gamma}\left[f\left(M_{p, i}, K_{p, i}^{h}, K_{p, i}^{f}\right)\right]^{\gamma-1} \frac{\partial f(\cdot)}{\partial M_{p, i}}=w_{p} \\
& \frac{\partial \pi_{p, i}}{\partial K_{p, i}^{h}}=0 \Rightarrow s_{p, i} A_{p, i} \gamma\left(N_{p, i}\right)^{1-\gamma}\left[f\left(M_{p, i}, K_{p, i}^{h}, K_{p, i}^{f}\right)\right]^{\gamma-1} \frac{\partial f(\cdot)}{\partial K_{p, i}^{h}}=r_{p} \\
& \frac{\partial \pi_{p, i}}{\partial N_{p, i}}=0 \Rightarrow s_{p, i} A_{p, i}(1-\gamma)\left[f\left(M_{p, i}, K_{p, i}^{h}, K_{p, i}^{f}\right)\right]^{\gamma} N_{p, i}^{-\gamma}=w_{p}
\end{aligned}
$$

Assuming the specific functional form $(2)$ for $f(\cdot)$, the partial derivatives of $f(\cdot)$ with respect to $M_{p, i}$ and $K_{p, i}^{h}$ are

$$
\begin{aligned}
& \frac{\partial f(\cdot)}{\partial M_{p, i}}=\alpha\left(M_{p, i}\right)^{\alpha-1}\left(K_{p, i}{ }^{h}\right)^{\beta}\left(K_{p, i}^{f}\right)^{\delta_{i}} \\
& \frac{\partial f(\cdot)}{\partial K_{p, i}^{h}}=\beta\left(M_{p, i}\right)^{\alpha}\left(K_{p, i}{ }^{h}\right)^{-(1-\beta)}\left(K_{p, i}^{f}\right)^{\delta_{i}}
\end{aligned}
$$

In the main text we only made the hypothesis that labour was employed in the optimal amount by the multinational company. Now we also make the hypothesis that the firm is employing an optimal amount of home capital. This enables us to further simplify the equilibrium relations. Taking the ratio of (10) and (11) we get

$$
M_{p, i}=\frac{r_{p}}{w_{p}} \frac{\alpha}{\beta} K_{p, i}^{h}
$$

expressing the equilibrium relation between labour employed in the final-good sector and home capital. Keeping constant the ratio between the rental rate and the wage rate, labour employed in the production of the final good is a linear function of home capital.

From (12), the equilibrium value for labor employed in the intermediate good's sector is

$$
N_{p, i}=\left[\frac{s_{p, i} A_{p, i}}{w_{p}}(1-\gamma)\right]^{1 / \gamma}\left(M_{p, i}\right)^{\alpha}\left(K_{p, i}^{h}\right)^{\beta}\left(K_{p, i}^{f}\right)^{\delta_{i}}
$$

Substituting the equilibrium value of $M_{p, i}$ from (13), we have

$$
N_{p, i}=\left[\frac{s_{p, i} A_{p, i}}{w_{p}}(1-\gamma)\right]^{1 / \gamma}\left(\frac{r_{p}}{w_{p}} \frac{\alpha}{\beta}\right)^{\alpha}\left(K_{p, i}^{h}\right)^{\alpha+\beta}\left(K_{p, i}^{f}\right)^{\delta_{i}}
$$

where labor employed in the production of intermediates is an increasing function of capital at home. Finally, total labor demand $\left(M_{p, i}+N_{p, i}\right)$ is equal to

$$
M_{p, i}+N_{p, i}=\frac{r_{p}}{w_{p}} \frac{\alpha}{\beta} K_{p, i}^{h}+\left[\frac{s_{p, i} A_{p, i}}{w_{p}}(1-\gamma)\right]^{1 / \gamma}\left(\frac{r_{p}}{w_{p}} \frac{\alpha}{\beta}\right)^{\alpha}\left(K_{p, i}^{h}\right)^{\alpha+\beta}\left(K_{p, i}^{f}\right)^{\delta_{i}}
$$

We assume a perfectly elastic labour supply again, at the wage $w_{p}$ prevailing in each province. The equilibrium relationship (15) says that the total amount of labour employed at home is an increasing function of home capital. As to foreign capital, there is 
complementarity or substitutability with home labour (and home production) depending on whether $\delta_{i}$ is positive or negative. Taking separately the logarithm for $M_{p, i}$ and $N_{p, i}$, and then differentiating with respect to time we get

$$
\begin{aligned}
\frac{\mathrm{d} M_{p, i}}{M_{p, i}} & =\frac{\mathrm{d}\left(r_{p} / w_{p}\right)}{r_{p} / w_{p}}+\frac{\mathrm{d} K_{p, i}^{h}}{K_{p, i}^{h}} \\
\frac{\mathrm{d} N_{p, i}}{N_{p, i}} & =\frac{1}{\gamma} \frac{\mathrm{d}\left(s_{p, i} A_{p, i}\right)}{s_{p, i} A_{p, i}}-\frac{1}{\gamma} \frac{\mathrm{d} w_{p}}{w_{p}}+\alpha \frac{\mathrm{d}\left(r_{p} / w_{p}\right)}{r_{p} / w_{p}}+(\alpha+\beta) \frac{\mathrm{d} K_{p, i}^{h}}{K_{p, i}^{h}}+\delta_{i} \frac{\mathrm{d} K_{p, i}^{f}}{K_{p, i}^{f}} \\
& =\frac{1}{\gamma} \frac{\mathrm{d} A_{p, i}}{A_{p, i}}+\frac{1}{\gamma} \frac{\mathrm{d}\left(\phi_{p} / w_{p}\right)}{\phi_{p} / w_{p}}+\alpha \frac{\mathrm{d}\left(r_{p} / w_{p}\right)}{r_{p} / w_{p}}+(\alpha+\beta) \frac{\mathrm{d} K_{p, i}^{h}}{K_{p, i}^{h}}+\delta_{i} \frac{\mathrm{d} K_{p, i}^{f}}{K_{p, i}^{f}}+\frac{1}{\gamma} \frac{\mathrm{d} \lambda_{i}}{\lambda_{i}}
\end{aligned}
$$

In our data, we are unable to observe separately the growth rates of labour in the final-good sector and labour in the intermediate-good sector. What we observe is the total growth rate of employment $\mathrm{d}\left(L_{p, i}\right) /\left(L_{p, i}\right)$, where $L_{p, i} \equiv M_{p, i}+N_{p, i}$. We should then assess the link between the theoretical growth rates (16) and (17) and the growth rate of (observable) total employment $L_{p, i}$,

$$
\frac{\mathrm{d} L_{p, i}}{L_{p, i}}=a_{1} \frac{\mathrm{d}\left(s_{p, i} A_{p, i}\right)}{s_{p, i} A_{p, i}}+a_{2} \frac{\mathrm{d} w_{p}}{w_{p}}+a_{3} \frac{\mathrm{d}\left(r_{p} / w_{p}\right)}{r_{p} / w_{p}}+a_{4} \frac{\mathrm{d} K_{p, i}^{h}}{K_{p, i}^{h}}+a_{5}^{i} \frac{\mathrm{d} K_{p, i}^{f}}{K_{p, i}^{f}}
$$

written here as a linear approximation of the growth rates of nominal productivity, local wages, the ratio between rental rate and the wage rate, home capital, foreign capital, and the price of the final good.

Since the growth rates in (16) and (17) both depend positively on variations in home capital, $K_{p, i}^{h}$, and on variations in the ratio between the rental rate and the wage rate, $r_{p} / w_{p}$, the expected sign of $a_{3}$ and $a_{4}$ is positive. In addition, the variation in $M_{p, i}$ can be explained by variation in $r_{p} / w_{p}$ and $K_{p, i}^{h}$ only, due to the assumptions we made (a specific functional form for $f(\cdot)$ and maximization with respect to home capital and labour).

On the contrary, from (17), also $s_{p, i} A_{p, i}, w_{p}$, and $K_{p, i}^{f}$ affect the variation in the intermediate good's labour in addition to $K_{p, i}^{h}$ and $r_{p} / w_{p}$. The result however is that the sign of coefficients in (19) on these variables should be the same of (17). We expect $a_{1}$ to be positive, $a_{2}$ to be negative, and the sign of $a_{5}^{i}$ to be the same of $\delta_{i}{ }^{19}$ The implications on the expected sign of the coefficients on the variables of interest are the same as the model described in the text.

\footnotetext{
${ }^{19}$ Conclusions are similar employing (18) instead of (17), and comparing it with a corresponding equation decomposing local price $s_{p, i}$ in the two components, $\phi_{p}$ and $\lambda_{i}$.
} 


\subsection{List of manufacturing industries}

The list of manufacturing industries analyzed in the paper follows. In parenthesis we report the corresponding Ateco 2002 classification (in turn derived from the Nace Rev. 1.1 classification). The level of aggregation generally corresponds to the two-letters classification, except in some cases where data are disaggregated up to a two-digits level. The matching is provided by UIC.

Non-metallic mineral products $(14,26)$; Chemicals and chemical products (24); Basic metals and fabricated metal products (27, 28); Machinery and equipment (29); Electric, electronic products $(31,32,33)$; Office, accounting and computing machinery (30); Transport equipment $(34,35)$; Food products, beverages and tobacco $(15,16)$; Textiles, textile products, leather and footwear $(17,18,19)$; Pulp, paper, paper products, printing and publishing $(21,22)$; Plastics and rubber products (25); Wooden products, furniture, toys, sportswear, other manufacturing $(20,36)$.

\subsection{List of countries}

Advanced countries: Andorra, Australia, Austria, Belgium, Canada, Denmark, Finland, France, Germany, Greece, Hong Kong, Iceland, Ireland, Israel, Japan, Mexico, Netherlands, New Zealand, Norway, Portugal, Singapore, South Korea, Spain, Sweden, Switzerland, Taiwan, United Kingdom, United States, Vatican City. Small countries: Bahamas, Bermuda, British Virgin Isles, Cayman Islands, Dutch Antilles, Gibraltar, Guernsey, Jersey, Liechtenstein, Luxembourg, Madeira, Malta, Monaco, Panama. Developing countries: all the remaining countries.

\subsection{The distribution of FDI by province-industry}

The cumulative distribution function for total foreign direct investments in P-I over the period 1997-2000 is strongly asymmetric. If we concentrate only on those P-I displaying positive values of FDI, the distributions can be graphically approximated by a lognormal. In Figure 1 we plot the logarithm of the sum of FDI in each province-industry from 1997 to 2000. Superimposed on the plot is a line joining the first and third quartiles of the distribution of the sample (a robust linear fit of the sample order statistics). This line is extrapolated out to the ends of the sample to help evaluate the linearity of the data. 
Performing the Lilliefors normality test, the $p$-value is 0.038 , so that we reject the null hypothesis of normality at a significance level of $5 \%$, while we cannot reject it at a significance level of $3 \%$. In addition we should keep in mind that the obligation for Italian residents to declare FDI concerns only those investments above 10,000 euros (in the logarithmic scale this means above 2.3), precisely the threshold above which we get a dense number of observations. We can therefore conclude the normality of the logarithm of the data.

[Insert Figure 1 about here]

A second way to look at FDI data is to see whether there are significant changes in their distribution across years. Consequently we take each elementary observation from the UIC dataset (the absolute value of flows from a given P-I in a given year) putting on the horizontal axis the logarithm of the rank (in descending order) and on the vertical axis the logarithm of the value FDI takes in a certain year. As can be seen from Fig. 2, the distribution across years is remarkably similar, indicating that the same stochastic process generates the data across different years. By the way, this makes us more confident on the aggregation of FDI from 1997 to 2000.

[Insert Figure 2 about here] 


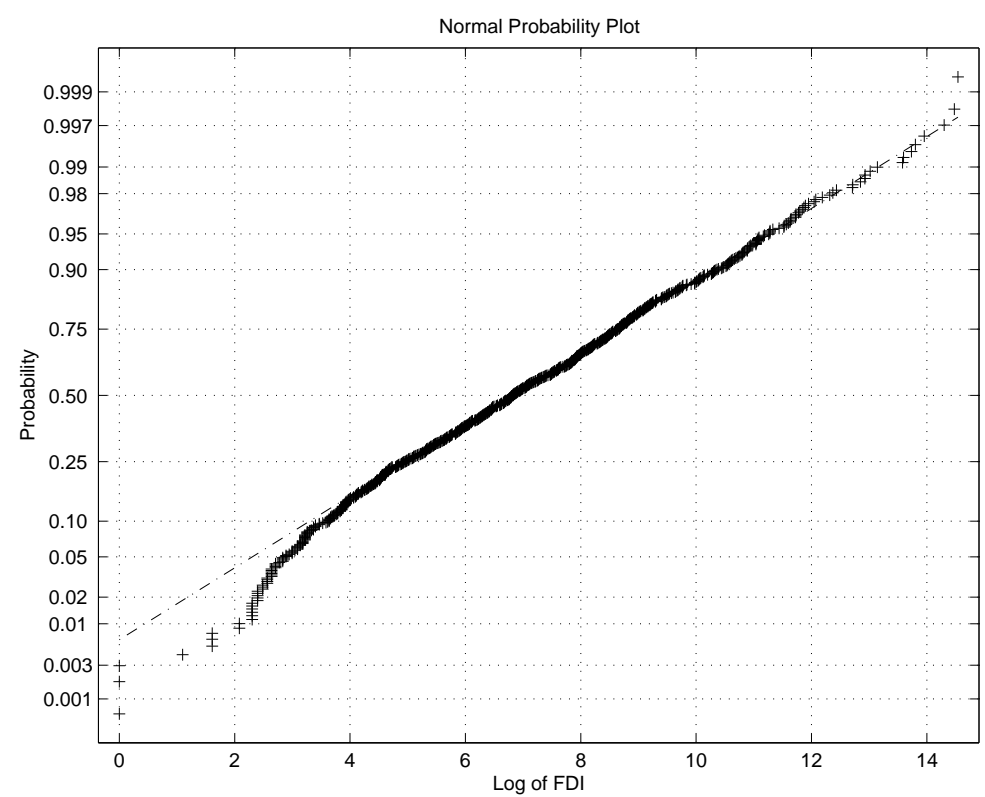

Figure 1: The plot of the logarithm of the sum of FDI flows from 1997 to 2000 for those P-I showing positive investment abroad is approximately distributed as a normal function.

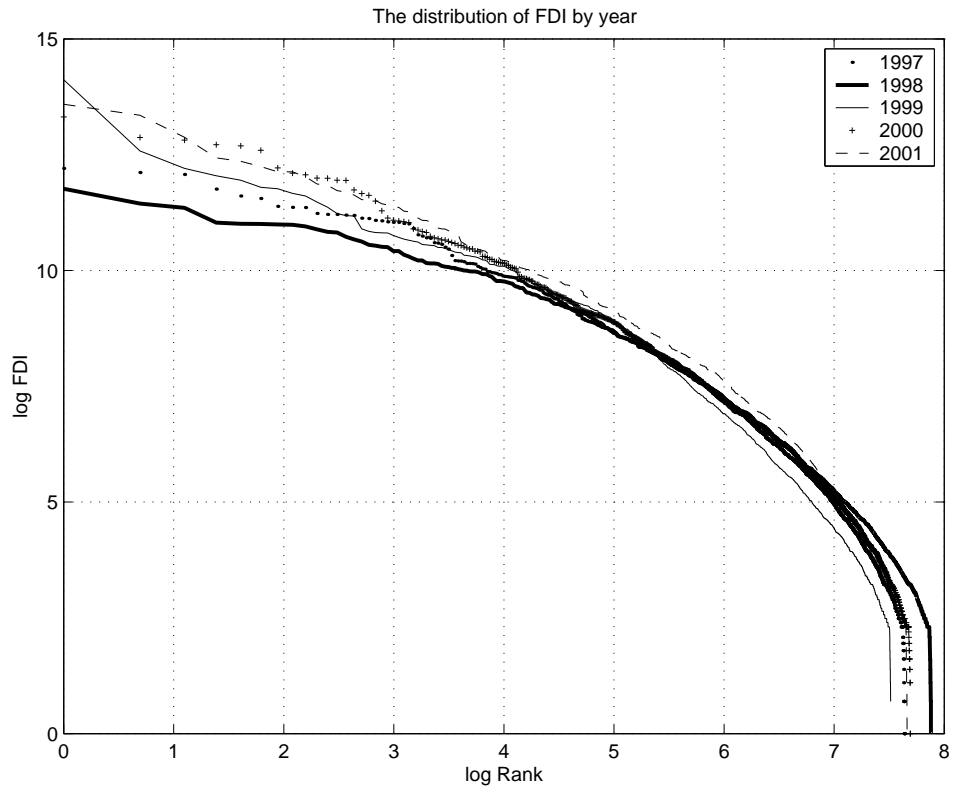

Figure 2: In the rank-size space, the distributions of FDI in each P-I for every year appear to be remarkably similar. 
Employment change and FDI share by region

\begin{tabular}{llcccc}
\hline & $\begin{array}{l}\text { empl. } \\
\text { change }\end{array}$ & $\begin{array}{c}\text { share } \\
\mathrm{fdi}^{\mathrm{W}}\end{array}$ & $\begin{array}{c}\text { of which: } \\
\mathrm{fdi}^{\mathrm{A}}\end{array}$ & $\begin{array}{c}\text { of which: } \\
\mathrm{fdi}^{\mathrm{D}}\end{array}$ & $\begin{array}{c}\text { of which: } \\
\mathrm{fdi}^{\mathrm{S}}\end{array}$ \\
\hline $\begin{array}{l}\text { Top three } \\
\text { Emilia-Romagna }\end{array}$ & 25.9 & 7.2 & 5.1 & 1.0 & 1.1 \\
Puglia & 16.7 & 0.7 & 0.6 & 0.0 & 0.1 \\
Veneto & 16.6 & 5.8 & 4.2 & 0.5 & 1.0 \\
Bottom three & & & & & \\
Lazio & -13.7 & 3.9 & 3.6 & 0.2 & 0.1 \\
Piemonte & -16.7 & 31.4 & 20.8 & 8.6 & 2.0 \\
Lombardia & -53.2 & 43.3 & 36.9 & 2.6 & 3.7 \\
Italy & $\mathbf{4 3 . 4}$ & $\mathbf{1 0 0 . 0}$ & $\mathbf{7 6 . 8}$ & $\mathbf{1 3 . 8}$ & $\mathbf{9 . 3}$ \\
\hline
\end{tabular}

Table 1: The table reports the absolute change (in thousands of people) in manufacturing employment between 1996-2001 for the three top and bottom-performing (in absolute terms) regions and their share on total manufacturing FDI outflows over the period 1997-2000.

Employment change and FDI share by industry

\begin{tabular}{llcccc}
\hline & $\begin{array}{c}\text { empl. } \\
\text { change }\end{array}$ & $\begin{array}{c}\text { share } \\
\mathrm{fdi}^{\mathrm{W}}\end{array}$ & $\begin{array}{c}\text { of which: } \\
\mathrm{fdi}^{\mathrm{A}}\end{array}$ & $\begin{array}{c}\text { of which: } \\
\mathrm{fdi}^{\mathrm{D}}\end{array}$ & $\begin{array}{c}\text { of which: } \\
\mathrm{fdi}^{\mathrm{S}}\end{array}$ \\
\hline Top three & & & & & \\
Metal products & 82.5 & 3.9 & 2.9 & 0.4 & 0.7 \\
Industrial machinery & 44.8 & 14.2 & 12.0 & 1.0 & 1.2 \\
Office equipment & 6.9 & 17.0 & 15.3 & 0.7 & 1.0 \\
Bottom three & & & & & \\
Chemical products & -3.2 & 10.2 & 8.3 & 1.2 & 0.7 \\
Transport vehicles & -5.4 & 13.8 & 5.3 & 7.2 & 1.2 \\
Textiles, apparel, leather & -108.5 & 5.9 & 4.6 & 0.8 & 0.5 \\
Total manufacturing & $\mathbf{4 3 . 4}$ & $\mathbf{1 0 0 . 0}$ & $\mathbf{7 6 . 8}$ & $\mathbf{1 3 . 8}$ & $\mathbf{9 . 3}$ \\
\hline
\end{tabular}

Table 2: The table reports the absolute change (in thousands of people) in manufacturing employment between 1996-2001 for the three top and bottom-performing (in absolute terms) industries and their share on total manufacturing FDI outflows over the period 1997-2000. 
Descriptive Statistics

\begin{tabular}{lcccccc}
\hline & obs. & median & mean & st. dev. & min. & max. \\
\hline$l_{p, i}$ & 1208 & 0.06 & 0.09 & 0.41 & -4.36 & 3.86 \\
spec & 1208 & -2.83 & -3.04 & 1.34 & -8.77 & -0.17 \\
size & 1208 & 2.00 & 2.08 & 0.83 & 0 & 5.87 \\
div & 1236 & 1.84 & 1.75 & 0.30 & 0.24 & 2.23 \\
$\mathrm{fdi}^{\mathrm{W}}$ & 1236 & 5.11 & 4.69 & 3.85 & 0 & 14.50 \\
$\mathrm{fdi}^{\mathrm{A}}$ & 1236 & 4.42 & 4.21 & 3.76 & 0 & 14.42 \\
fdi $^{\mathrm{D}}$ & 1236 & 0 & 2.17 & 3.16 & 0 & 14.16 \\
$\exp ^{\mathrm{W}}$ & 1235 & 4.94 & 4.51 & 2.54 & -7.50 & 10.07 \\
gtfp & 901 & 0.03 & 0.02 & 0.33 & -4.51 & 1.54 \\
gcap & 901 & 0.28 & 0.31 & 0.56 & -5.69 & 4.21 \\
$\mathrm{tfp}$ & 901 & 4.73 & 4.78 & 0.54 & 3.11 & 7.69 \\
\hline
\end{tabular}

Table 3: The table reports descriptive statistics for selected variables. The suffix $\mathrm{W}$ after fdi or exp denotes flows to all world countries; A and D denote respectively advanced and developing countries (see Appendix 8.3).

\section{Correlation matrix among variables}

\begin{tabular}{|c|c|c|c|c|c|c|c|c|c|c|c|}
\hline & $l_{p, i}$ & spec & size & div & $\mathrm{fdi}^{\mathrm{W}}$ & $\mathrm{fdi}^{\mathrm{A}}$ & $\mathrm{fdi}^{\mathrm{D}}$ & gtfp & gcap & tfp & $\exp ^{\mathrm{W}}$ \\
\hline$l_{p, i}$ & 1 & & & & & & & & & & \\
\hline spec & -0.29 & 1 & & & & & & & & & \\
\hline size & -0.17 & 0.00 & 1 & & & & & & & & \\
\hline div & -0.04 & 0.13 & 0.15 & & & & & & & & \\
\hline $\mathrm{fdi}^{\mathrm{W}}$ & -0.10 & 0.14 & 0.28 & 0.13 & 1 & & & & & & \\
\hline $\mathrm{fdi}^{\mathrm{A}}$ & -0.09 & 0.11 & 0.28 & 0.14 & 0.95 & 1 & & & & & \\
\hline $\mathrm{fdi}^{\mathrm{D}}$ & -0.11 & 0.24 & 0.16 & 0.11 & 0.71 & 0.62 & 1 & & & & \\
\hline $\exp ^{\mathrm{W}}$ & -0.17 & 0.44 & 0.46 & 0.14 & 0.65 & 0.61 & 0.56 & 1 & & & \\
\hline gtfp & -0.01 & 0.08 & -0.04 & 0.02 & 0.07 & 0.08 & 0.06 & 0.07 & 1 & & \\
\hline gcap & 0.05 & -0.02 & -0.06 & 0.05 & -0.01 & -0.02 & -0.01 & 0.01 & 0.03 & 1 & \\
\hline $\mathrm{tfp}$ & -0.04 & 0.12 & 0.32 & 0.09 & 0.27 & 0.27 & 0.19 & 0.37 & -0.10 & -0.02 & 1 \\
\hline
\end{tabular}

Table 4: The table reports pairwise correlation coefficients among selected variables. The suffix W after fdi or exp denotes flows to all world countries; A and D denote respectively advanced and developing countries (see Appendix 8.3). 
Local employment growth

\begin{tabular}{lcccc}
\hline & {$[1]$} & {$[2]$} & {$[3]$} & {$[4]$} \\
\hline spec & $-0.085^{* *}$ & $-0.089^{* *}$ & $-0.145^{* * *}$ & $-0.149^{* * *}$ \\
& $(0.040)$ & $(0.041)$ & $(0.043)$ & $(0.044)$ \\
$\operatorname{div}$ & $0.164^{* *}$ & $0.157^{* *}$ & 0.087 & 0.081 \\
& $(0.071)$ & $(0.071)$ & $(0.071)$ & $(0.070)$ \\
size & $-0.154^{* * *}$ & $-0.152^{* * *}$ & $-0.169^{* * *}$ & $-0.167^{* * *}$ \\
& $(0.048)$ & $(0.048)$ & $(0.049)$ & $(0.049)$ \\
$\left(\right.$ fdi $\left.^{\mathrm{W}}+1\right)$ & $0.017^{* * *}$ & - & $0.012^{* *}$ & - \\
& $(0.005)$ & & $(0.005)$ & \\
$\left(\right.$ fdi $\left.^{\mathrm{A}}+1\right)$ & - & $0.016^{* * *}$ & - & $0.011^{* *}$ \\
& & $(0.005)$ & & $(0.005)$ \\
$\left(\mathrm{fdi}{ }^{\mathrm{D}}+1\right)$ & - & 0.006 & - & 0.006 \\
& & $(0.005)$ & & $(0.005)$ \\
exp & & - & $0.069^{* * *}$ & $0.068^{* * *}$ \\
& - & & $(0.016)$ & $(0.016)$ \\
\hline spt ctrls & Yes & Yes & Yes & Yes \\
ind ctrls & Yes & Yes & Yes & Yes \\
$\mathrm{R}_{\text {-squared }}$ & 0.27 & 0.27 & 0.29 & 0.29 \\
no. obs. & 1208 & 1208 & 1208 & 1208 \\
\hline & & & &
\end{tabular}

Table 5: The table reports the results of OLS regressions which include dummies for each province and each industry. The dependent variable is the growth rate of employment in local plants. The suffix W after fdi or exp denotes flows to all world countries; A and D denote respectively advanced and developing countries (see Appendix 8.3). White-adjusted Standard errors are in parentheses. $* * *, * *$ and $*$ denote significance at the 1,5 and 10 per cent level. 
Local employment growth in a subsample of P-Is

\begin{tabular}{lccc}
\hline & {$[1]$} & {$[2]$} & {$[3]$} \\
\hline spec & $-0.084^{* * *}$ & $-0.084^{* * *}$ & $-0.082^{* * *}$ \\
\multirow{2}{*}{$\operatorname{div}$} & $(0.025)$ & $(0.024)$ & $(0.024)$ \\
& 0.071 & 0.069 & 0.058 \\
size & $(0.066)$ & $(0.067)$ & $(0.068)$ \\
& $-0.122^{* * *}$ & $-0.123^{* * *}$ & $-0.136^{* * *}$ \\
$\left(\right.$ fdi $\left.^{\mathrm{W}}+1\right)$ & $(0.034)$ & $(0.034)$ & $(0.035)$ \\
& $0.006^{*}$ & $0.006^{*}$ & $0.006^{*}$ \\
exp ${ }^{\mathrm{W}}$ & $(0.004)$ & $(0.004)$ & $(0.004)$ \\
& $0.048^{* *}$ & $0.049^{* *}$ & $0.046^{* *}$ \\
gtfp & $(0.019)$ & $(0.019)$ & $(0.019)$ \\
& - & -0.032 & -0.015 \\
gcap & & $(0.031)$ & $(0.031)$ \\
& - & -0.002 & -0.004 \\
tfp & - & $(0.014)$ & $(0.014)$ \\
& & - & $0.058^{* *}$ \\
\hline spt ctrls & Yes & Yes & $(0.023)$ \\
ind ctrls & Yes & Yes & Yes \\
R-squared & 0.31 & 0.31 & Yes \\
no. obs. & 899 & 899 & 899 \\
\hline
\end{tabular}

Table 6: The table reports the results of OLS regressions which include dummies for each province and each industry. The dependent variable is the growth rate of employment in local plants. The suffix W after fdi or exp denotes flows to all world countries. White-adjusted Standard errors are in parentheses. ${ }^{* * *},{ }^{* *}$ and $*$ denote significance at the 1,5 and 10 per cent level. 


\section{$F$-test on the sum of FDI coefficient and the interaction term}

\begin{tabular}{lccc}
\hline & FDI world & FDI advanced & FDI developing \\
\hline Non-metallic products & $0.000\left(\alpha_{1}\right)$ & $0.000\left(\alpha_{1}\right)$ & $0.001\left(\alpha_{1}\right)$ \\
Chemical products & $0.025^{* *}$ & $0.023^{* *}$ & $0.019^{*}$ \\
Metal products & 0.006 & 0.005 & 0.006 \\
Industrial machinery & $0.024^{* *}$ & $0.024^{* *}$ & 0.015 \\
Office equipment & -0.004 & -0.002 & 0.006 \\
Electronic products & 0.009 & 0.009 & $0.015^{*}$ \\
Transport vehicles & 0.005 & 0.009 & 0.010 \\
Food and beverage & 0.011 & $0.011^{*}$ & 0.006 \\
Textiles, apparel, leather & 0.004 & 0.005 & 0.003 \\
Paper and printing & $0.016^{* *}$ & $0.017^{* *}$ & $0.024^{*}$ \\
Plastic and rubber products & 0.017 & $0.020^{* *}$ & 0.004 \\
Other manufacturing & 0.010 & 0.010 & 0.009 \\
\hline
\end{tabular}

Table 7: The table reports the sum of FDI coefficient and the interaction term, $\left(\alpha_{1}+\delta_{1, i}\right)$. The linear restriction to be tested is whether this sum is significantly greater than zero. In the regression we dropped the dummy for non-metallic mineral products, thus becoming the reference sector, because its estimated coefficient turns to be conveniently close to zero. ${ }^{* * *},{ }^{* *}$ and ${ }^{*}$ denote significance at the 1,5 and 10 per cent level. 


\section{Employment growth by plant size and in firms}

\begin{tabular}{lccc}
\hline & $\begin{array}{c}\text { less than } \\
50 \text { empl. }\end{array}$ & $\begin{array}{c}\text { 50 or more } \\
\text { empl. }\end{array}$ & $\begin{array}{c}\text { empl. in } \\
\text { firms }\end{array}$ \\
\hline spec & $-0.118^{* * *}$ & $-0.071^{*}$ & $-0.154^{* * *}$ \\
& $(0.034)$ & $(0.040)$ & $(0.053)$ \\
div & 0.078 & 0.063 & 0.118 \\
& $(0.063)$ & $(0.098)$ & $(0.092)$ \\
size & -0.002 & $-0.224^{* * *}$ & -0.067 \\
& $(0.043)$ & $(0.047)$ & $(0.070)$ \\
$\left(\right.$ fdi $\left.{ }^{\mathrm{W}}+1\right)$ & 0.005 & $0.012^{*}$ & 0.008 \\
& $(0.005)$ & $(0.007)$ & $(0.006)$ \\
exp ${ }^{\mathrm{W}}$ & $0.049^{* * *}$ & 0.025 & $0.069^{* * *}$ \\
& $(0.016)$ & $(0.022)$ & $(0.019)$ \\
\hline spt ctrls & Yes & Yes & Yes \\
ind ctrls & Yes & Yes & Yes \\
R-squared & 0.24 & 0.24 & 0.19 \\
no. obs. & 1207 & 940 & 1207 \\
\hline
\end{tabular}

Table 8: The table reports the results of OLS regressions which include dummies for each province and each industry. In the first column the dependent variable is the growth rate of employment in plants with less than 50 employees in local plants (50 or more in the second column); in the last column it is the growth rate of employment in firms located in the P-I. The suffix W after fdi or exp denotes flows to all world countries. White-adjusted Standard errors are in parentheses. ***, ** and $*$ denote significance at the 1,5 and 10 per cent level. 


\section{References}

[1] Antràs P. (2004), Firms, Contracts and Trade Structure, Quarterly Journal of Economics, 118, 1375-1418.

[2] Banca d'Italia (2006), Indagine sulle imprese industriali e dei servizi. Anno di riferimento 2004, Supplementi al Bollettino Statistico. Indagini campionarie, XVI, n. 3-4, Roma.

[3] Banca d'Italia, Ufficio Italiano dei Cambi (2004), Manuale della bilancia dei pagamenti e della posizione patrimoniale dell'Italia sull'estero, Roma.

[4] Barba Navaretti G., Castellani D. (2004), Investments Abroad and Performance at Home: Evidence from Italian Multinationals, CEPR Working Paper, n. 4284.

[5] Barba Navaretti G., Venables A.J. et al. (2004), Multinational firms in the world economy, Princeton, Princeton University Press.

[6] Basevi G., Ottaviano G.I.P. (2002), The District and the Global Economy: Exportation versus Foreign Relocation, Journal of Regional Science, 42, 107-126.

[7] Blomstrom M., Fors G., Lipsey R.E. (1997), Foreign Direct Investment and Employment: Home-Country Experience in the United States and Sweden, The Economic Journal, 107, 1787-1797.

[8] Braconier H., Ekholm K. (2000), Swedish Multinationals and Competition from Highand Low-Wage Locations, Review of International Economics, 8, 448-461.

[9] Brainard S. L., Riker D. A. (1997), Are U.S. Multinationals Exporting U.S. Jobs?, NBER Working Paper, n. 5958.

[10] Bruno G., Falzoni A.M. (2003), Multinational corporations, wages and employment: Do adjustment costs matter?, Applied Economics, 35, 1277-1290.

[11] Cingano F., Schivardi F. (2004), Identifying the Sources of Local Productivity Growth, Journal of the European Economic Association, 4, 720-742.

[12] Combes, P.-P. (2000), Economic Structure and Local Growth: France, 1984-1993, Journal of Urban Economics, 47, 329-355.

[13] Combes P.-P., Magnac T., Robin J.-M. (2004), The Dynamics of Local Employment in France, Journal of Urban Economics, 56, 217-243.

[14] Cominotti R., Mariotti S., Mutinelli M., Piscitello L. (2002), Italia multinazionale 2000, Documenti del Consiglio Nazionale dell'Economia e del Lavoro, Roma. 
[15] Committeri M. (1999), Errori e omissioni nella bilancia dei pagamenti, esportazioni di capitali e apertura finanziaria dell'Italia, Temi di Discussione del Servizio Studi della Banca d'Italia, n. 352.

[16] Federico S. (2006), L'internazionalizzazione produttiva italiana e i distretti industriali: un'analisi degli investimenti diretti all'estero, Temi di Discussione del Servizio Studi della Banca d'Italia, forthcoming.

[17] Glaeser E. L., Kallal H. D., Scheinkman J. A., Shleifer A. (1992), Growth in Cities, Journal of Political Economy, 100, 1126-1152.

[18] Head K., Ries J. (2002), Offshore Production and Skill Upgrading by Japanese Manufacturing Firms, Journal of International Economics, 58, 81-105.

[19] Helpman H., Melitz M. J., Yeaple S. R. (2004), Export Versus FDI with Heterogeneous Firms, American Economic Review, 94, 300-316.

[20] Henderson V., Kuncoro A., Turner M. (1995), Industrial Development in Cities, Journal of Political Economy, 103, 1067-1090.

[21] International Monetary Fund (1993), Balance of Payments Manual, 5th edition, Washington DC.

[22] Konings J., Murphy A. (2001), Do multinational enterprises substitute parent jobs for foreign ones? Evidence from European firm-level panel data, CEPR Working Paper, n. 2972.

[23] Levinsohn J., Petrin A. (2003) Estimating Production Functions Using Inputs to Control for Unobservables, Review of Economic Studies, 70, 317-341.

[24] Lipsey R.E. (2001), Foreign Direct Investment and the Operations of Multinational Firms: Concepts, History and Data, NBER Working Paper, n. 8665.

[25] Lipsey R.E. Ramstetter E., Blomstrom M. (2000), Outward FDI and Parent Exports and Employment: Japan, the United States and Sweden, Global Economic Quarterly, 1, 285-302.

[26] Mariotti S., Mutinelli M., Piscitello L. (2003), Home country employment and foreign direct investment: evidence from the Italian case, Cambridge Journal of Economics, 27, 419-431.

[27] Petrin A., Levinsohn J. (2005) Measuring Aggregate Productivity Growth Using Plant-level Data, mimeo.

[28] Redding S., Venables A.J. (2004), Economic geography and international inequality, Journal of International Economics, 62, 53-82. 